\title{
Tomography of the Chukou Fault Zone, Southwest Taiwan: Insights from Microearthquake Data
}

\author{
Yu-Lien Yeh ${ }^{1}$, Strong Wen ${ }^{2, *}$, Wei-Cheng Chien ${ }^{1}$, Yi-Zen Chang ${ }^{2}$, and Chau-Huei Chen ${ }^{1}$ \\ ${ }^{1}$ Department of Earth and Environmental Sciences, National Chung Cheng University, Chia-Yi, Taiwan, R.O.C. \\ ${ }^{2}$ National Center for Research on Earthquake Engineering, Taipei, Taiwan, R.O.C.
}

Received 1 September 2015, revised 15 January 2016, accepted 29 January 2016

\begin{abstract}
The vigorous collision between the Eurasian plate and Philippine Sea plate in Taiwan causes a series of imbricate fold and thrust belts to develop at the deformation front. The Chukou Fault (CKF), characterized by a thrust type fault, located in Chiayi County, southwest (SW) Taiwan, is a prominent boundary between the fold-thrust belts and the Western Coastal Plain. Most of the seismicity in SW Taiwan is associated with this fault and its neighboring fault systems. The seismotectonic structures in the CKF zone, especially in the east, are complex due to the interactions among fault systems with distinct slip motions. To gain better insights into the seismogenic characteristics in the CKF zone, we used 1661 microearthquakes recorded by a temporary dense broadband seismic network and the Central Weather Bureau Seismic Network (CWBSN) between 2003 and 2004 to investigate the physical properties of the crust in the CKF zone. A waveform cross-correlation technique was applied to 143086 pairs of waveform data to determine the relative differential travel time between the P- and S-waves. By combining both the absolute and relative differential travel time data, we were able to obtain a new 3-D crustal P-wave velocity structure and $\mathrm{V}_{\mathrm{p}} / \mathrm{V}_{\mathrm{s}}$ ratios. This study suggests that by using both absolute and relative differential travel time data in tomographic inversion can obtain precise 3-D velocity images and also gain better correlation between seismic events and fault structures, which is crucial for understanding the seismogenic process in our study area.
\end{abstract}

Key words: Chukuo Fault, 3-D velocity structure, $\mathrm{V}_{\mathrm{p}}, \mathrm{V}_{\mathrm{p}} / \mathrm{V}_{\mathrm{s}}$ ratio, Seismogenic zone

Citation: Yeh, Y. L., S. Wen, W. C. Chien, Y. Z. Chang, and C. H. Chen, 2016: Tomography of the Chukou Fault zone, southwest Taiwan: Insights from microearthquake data. Terr. Atmos. Ocean. Sci., 27, 387-396, doi: 10.3319/TAO.2016.01.29.01(TEM)

\section{INTRODUCTION}

Exploring the physical properties of an orogenic deformation front is a challenging task due to the complex nature of fold-thrust structures. One typical region is the Island of Taiwan, located at the collision boundary between the Eurasian plate and the Philippine Sea plate (Suppe 1985; Dahlen and Barr 1989; Wu et al. 1997). Ongoing mountainbuilding has caused the development of a series of active fault zones with a high seismic potential in the deformation front. A few models, somewhat contradictory, were proposed to explain the mechanisms of the orogenic process in Taiwan (e.g., Suppe 1981; Wu et al. 1997). Suppe (1981) proposed a thin-skinned hypothesis that describes the foldthrust belt in the deformation front formed above a décollement underlain by a relatively higher strength material.

\footnotetext{
* Corresponding author

E-mail: strong@eq.ccu.edu.tw
}

However, Wu et al. (1997) suggested a thick-skinned model that indicated the collision process in Taiwan as being with the whole crustal scale. Currently, there is insufficient data available to test these two end-member models for Taiwan orogeny. There is also a lack of information to investigate the details of the orogenic process. The geological structures of the western deformation front in Taiwan are characterized by imbricated structures, which include a fold and thrust belt (Suppe 1981; Brown et al. 2012). An example is the well-known Chenglongpu fault (CLF) located in the central segment of the deformation front, which caused the great 1999 Chi-Chi earthquake $\left(\mathrm{M}_{\mathrm{L}}=7.3\right)$. The rupture of the Chi-Chi earthquake was terminated at the southern end of the CLF, which is the Chukuo Fault (CKF) zone. The CKF is a prominent boundary between the Western Coastal Plain (WCP) and the Western Foothill (WF) (Fig. 1). According to GPS data, the average crustal shortening rate in 
the $\mathrm{CKF}$ is $6 \mathrm{~mm} \mathrm{yr}^{-1}$ ( $\mathrm{Yu}$ and Chen 1998), indicating rapid crustal deformation and stress accumulation, which could lead to increasing earthquake potential in this highly populated area. East of the CKF, a complex fault system exists (denoted by the solid red lines in Fig. 1) with different slip motions. The Neipang Fault (NPF) and Shuisheliao Fault (SSLF) are strike slip faults, while the faults in between are in thrust motion. The vicinity of the CKF zone is also characterized by very complex fault interactions and has been a major target area for seismic hazard mitigation in Taiwan. A first step towards earthquake mitigation is to possess better knowledge of the characteristics of seismogenic zone. Therefore, after the occurrence of 1999 Chi-Chi earthquake, one important task is to investigate the physical properties, seismic activities as well as the geometries of the seismogenic zones in southwest (SW) Taiwan.

An effective clue for understanding the fault zone characteristics is the spatial distribution of seismic events. It is therefore important to determine local earthquake hypocenters, which has not always been an easy task. Earthquake relocation is affected by many factors, such as local velocity structure, error in picking seismic phase arrival time and the different numerical techniques used to determine earth- quake hypocenters. Thus, how to choose an appropriate weighting among uneven distributed of events and stations during an inversion procedure becomes an inevitable challenge. Most earthquakes in the CKF zone have magnitudes $\left(\mathrm{M}_{\mathrm{L}}\right)$ less than 3 and occur in east of the CKF (denoted by the open circles in Fig. 1). The area in east of the CKF has high topography, which is lack of seismic stations. From 2003 to 2004, five years after the 1999 Chi-Chi earthquake, this study established a temporary broadband seismic array (CCU-net, Fig. 1) along the CKF to record high quality seismic data for one and half years. Our goals in this study include (1) relocate microearthquakes using a recent 1-D velocity model derived from seismic ambient noise, which has better constraints on the velocity structure in the uppermost crust and (2) derive 3-D velocity structures and $\mathrm{V}_{\mathrm{p}} / \mathrm{V}_{\mathrm{s}}$ ratios to investigate the characteristics of seismogeneric structure in the CKF zone .

Among different earthquake relocation techniques, the most commonly used methods are the HypoDD (Waldhauser and Ellsworth 2000) and the TomoDD (Zhang and Thurber 2003) programs. We applied both techniques to relocate earthquakes recorded by the Central Weather Bureau (CWB) and the abovementioned dense broadband seismic

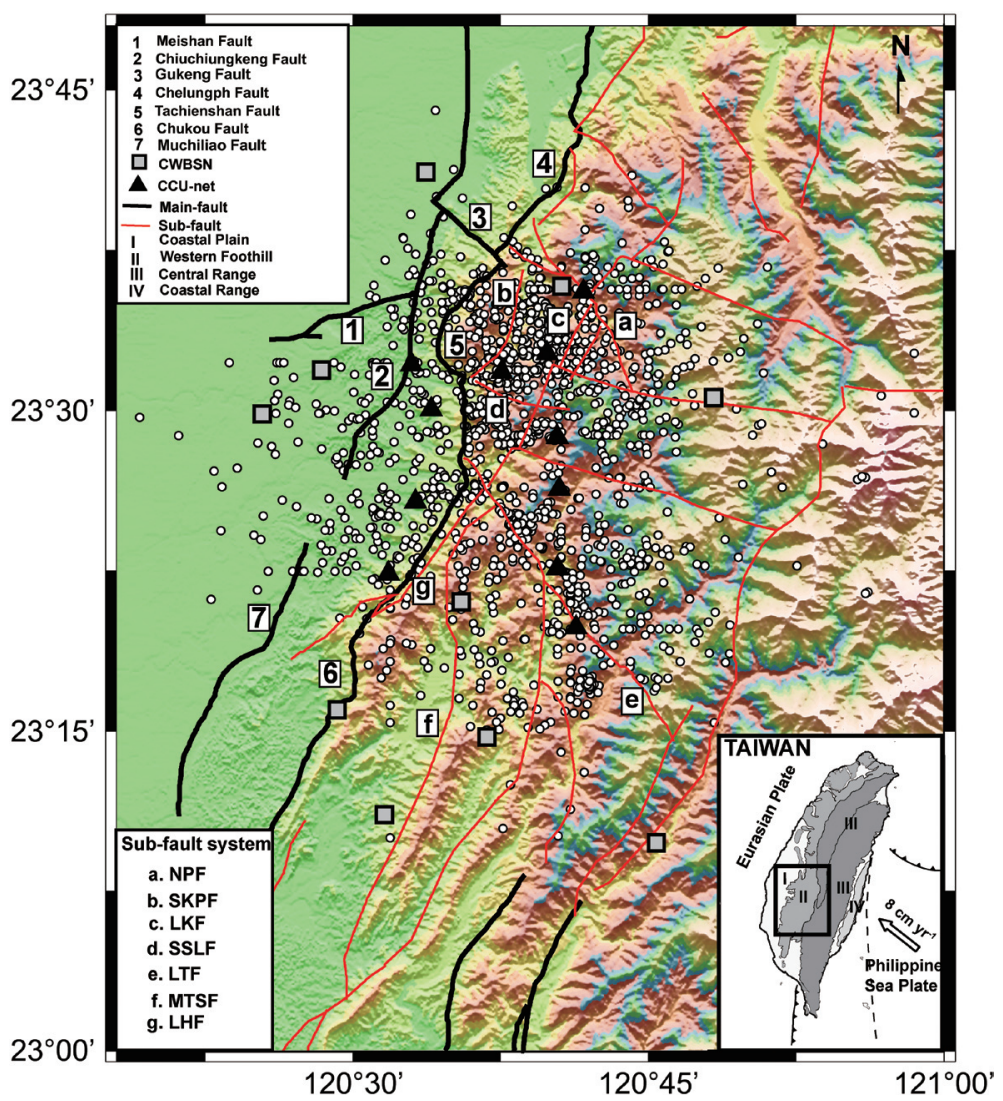

Fig. 1. Geological setting of the study area. Major faults are denoted by thick solid black lines, while thin red lines are sub-faults located in the hanging wall of the Chukou Fault (CKF). Black triangles (CCU-net) and white squares (CWBSN) indicate seismic stations deployed by National Chung Cheng University and Central Weather Bureau respectively. The inset map in the lower right-hand corner illustrates four geological units in Taiwan and the legend in the lower left corner shows abbreviation names of sub-faults. (Color online only) 
array. The most common previous approach used the absolute differential travel time (ADTT) between the P- and Swaves from catalogue data to relocate an earthquake. With an even station distribution and azimuth coverage, earthquake location may be well determined using catalogue data alone. However, this is usually not the case for most of the time. In order to overcome this problem, we applied the TomoDD technique which allows us to use both absolute and relative differential travel time (RDTT) between P- and Swaves. The RDTT was obtained using a waveform crosscorrelation (WCC) approach. The intention is to combine both data sets in a relocation procedure to improve the precision of determining earthquake location. Another benefit of applying the TomoDD technique is that it can simultaneously obtain seismic velocity structure. Several 3-D velocity models have been derived from travel-time data gathered across Taiwan (Rau and Wu 1995; Ma et al. 1996; Kim et al. 2005; Wu et al. 2007; Wang et al. 2009; Kuo-Chen et al. 2012), but the abovementioned regional velocity models are defined on a grid with a cell size that is too large to interpret local fault zones in detail. For SW Taiwan, Wen and Chen (2004) proposed a 3-D velocity structure, however, they also encountered low spatial resolution (grid size is $15 \times 10 \mathrm{~km}$ ). The seismic events that Wen and Chen (2004) used all possessed magnitudes greater than $3\left(\mathrm{M}_{\mathrm{L}}\right)$. Therefore, this study adopted local and regional data to gain more detailed 3-D crustal velocity structures that can give us new insights into the physical properties of the CKF zone. The results can be further used in seismic hazard assessment and mitigation in SW Taiwan.

\section{GEOLOGICAL SETTING}

SW Taiwan is divided into two geological provinces: (1) the WCP and (2) the WF. For the past century, several large earthquakes were recorded in the area. These include the 1906 Meishan earthquake (M 7.1), the 1941 Chungpu earthquake (M 7.1), the 1964 Paiho earthquake (M 6.3), the 1998 Ruey-Li earthquake (M 6.2), and the 1999 Chiayi earthquake (M 6.4). It is worth noting that all of these events occurred within the upper crust and caused many casualties in this highly populated area. The major active faults in our study area can be categorized into two types: strike-slip and thrust. Two strike-slip faults include the Meisan Fault (MSF) with EW trending and the Gukeng Fault (GKF) is in NW direction. The Chiuchiungkeng Fault (CCKF) and the CKF are in N-S strike direction and both present thrust slip motion (Fig. 1). A complex sub-fault system located in the hanging wall of the CKF denoted by the lower-case alphabet is also depicted in Fig. 1. Thus, to gain a better knowledge of the seismotectonics in SW Taiwan, especially in the uppermost crustal region, becomes crucial. The complex subfault system in the eastern CKF zone region is characterized by mixing thrust faults and left-lateral strike-slip faults, which were responsible for the 1998 Ruey-Li earthquake sequence (Chen et al. 2003; Wen et al. 2008).

\section{METHOD AND DATA ANALYSIS}

In this section we present earthquake data processing and relocation procedures. In sections 3.1 and 3.2, we describe the process to estimate ADTT and RDTT between $\mathrm{P}$ - and S-waves respectively. The procedure of relocating earthquakes will be briefly described in section 3.3 .

\subsection{Calculating ADTT Between P-and S-Waves}

Between August 2003 and December 2004, 11 temporary broadband seismic stations were deployed in the CKF zone (denoted by solid black triangles in Fig. 1; also see Table 1). In addition, the CWB also deployed ten permanent seismic stations (denoted by the gray squares in Fig. 1) belonging to the network called Central Weather Bureau Seismic Network (CWBSN). Table 1 lists the locations of seismic stations used in this study. The longitudes in this study area range between 120.3 and $120.9^{\circ}$, while the latitudes range from $23.1-23.8^{\circ}$. The criterion for event selection is

Table 1. Station list in this study.

\begin{tabular}{cccc}
\hline Station & Lat. & Lon. & Elev. $(\mathbf{m})$ \\
\hline spin & 23.5357 & 120.5495 & 232.00 \\
ghua & 23.4793 & 120.6727 & 500.00 \\
ltou & 23.4383 & 120.6745 & 1165.0 \\
clin & 23.5928 & 120.6948 & 1025.0 \\
xmei & 23.3282 & 120.6825 & 582.00 \\
tahu & 23.5300 & 120.6257 & 783.00 \\
ruli & 23.5445 & 120.6642 & 992.00 \\
ushu & 23.3730 & 120.5300 & 125.00 \\
smei & 23.3773 & 120.6720 & 538.00 \\
nepu & 23.4853 & 120.5663 & 231.00 \\
wtan & 23.4295 & 120.5532 & 154.00 \\
CHY & 23.4976 & 120.4233 & 27.000 \\
ALS & 23.5103 & 120.8050 & 2413.4 \\
WGK & 23.6861 & 120.5616 & 75.000 \\
WTP & 23.2455 & 120.6133 & 560.30 \\
STY & 23.1625 & 120.7566 & 640.00 \\
CHN1 & 23.1848 & 120.5266 & 360.00 \\
CHN2 & 23.5318 & 120.4733 & 50.000 \\
CHN4 & 23.3510 & 120.5916 & 205.00 \\
CHN5 & 23.5971 & 120.6766 & 840.00 \\
TWL & 23.2665 & 120.4866 & 590.00 \\
TWO1 & 23.5705 & 120.5933 & 231.00 \\
\hline & & &
\end{tabular}


that each event must be recorded by at least four stations. In order to ensure seismic data quantity and good station coverage, events recorded by the CWBSN stations will also be included. The preliminary event locations were determined using HYPO71 (Lee and Lahr 1972) and the epicenters are plotted in Fig. 1 (denoted by the solid white circles). There were 1661 events with $16108 \mathrm{P}$-wave and $14576 \mathrm{~S}$-wave readings, which were further used to calculate ADTT to perform HypoDD inversion. The locations of relocated events obtained from HypoDD were used to calculate a new set of ADTT. The flow chart of data processing and analysis is presented in Fig. 2.

\subsection{Calculating RDTT Between the P-and S-Waves}

We also calculated the RDTT between P- and S-waves through WCC to reduce phase picking error. The following data processing procedure was conducted to be consistent with the data recorded by the CWBSN: (1) we first resampled the waveform to 100 points per second; (2) rotated the data into the radial, tangential and vertical components; (3) obtained P- and S-waves readings; (4) the time window used in WCC is $0.64 \mathrm{~s}$ to avoid $\mathrm{P}$ - and S-waves overlapping. Furthermore, the RDTT was selected when the correlation coefficient was higher than 0.7 . Events within a $5 \mathrm{~km}$ radius were selected for WCC calculation. The representative WCC example between two distinct events recorded at station GHUA is illustrated in Fig. 3. Table 2 lists the total number of absolute (342202) and relative differential travel data (143086) used in the TomoDD inversion.

\subsection{Earthquake Relocation and Velocity Inversion}

The TomoDD technique developed by Zhang and Thurber (2003) is a hybrid method that combines the HypoDD (Waldhauser and Ellsworth 2000) and tomographic algorithms to locate an earthquake hypocenter and concurrently invert for velocity structure. Most of the previous studies used only the ADTTs between P- and S-waves in determining relative event locations. In this study, we include both the ADTT and the RDTT data to relocate seismic events and also to derive a better 3-D tomographic P-wave velocity structure. The great advantage of including the ADTT and RDTT data is to improve the event location precision and consequently a more realistic velocity structure. This method allows us to have better understanding of the seismogenic structures, especially east of the CKF, in the SW Taiwan deformation front.

\section{MODEL EXAMINATIONS: CHECKERBOARD TEST}

We performed a traditional checkerboard test to demonstrate the robustness of the inversion of our dataset in- cluding the ADTT and the RDTT data. In this test the initial velocity model consists of grids with alternating positive and negative velocity perturbations of $\pm 5 \%$. The initial 6-layer P-wave velocity model derived from Yeh et al. (2013) and $\mathrm{V}_{\mathrm{p}} / \mathrm{V}_{\mathrm{s}}$ ratio are shown in Table 3. After testing various grid sizes and velocity perturbations, we found that a grid size of $3 \times 3 \mathrm{~km}$ (cross symbols in Fig. 4a indicate inversion nodes) with $\pm 5 \%$ velocity perturbation alternatively are the best parameters to successfully recover the initial model. The grid size is smaller than that in earlier studies conducted by Wen and Chen (2004) and depicts better resolution for the $\mathrm{V}_{\mathrm{p}}$ structure (Fig. 4) as well as for the $\mathrm{V}_{\mathrm{p}} / \mathrm{V}_{\mathrm{s}}$ ratios (Fig. 5). Figure $4 \mathrm{~b}$ shows the tomographic $\mathrm{V}_{\mathrm{p}}$ perturbations in different depths and the values can be up to $\pm 12 \%$, which is beyond the $\pm 5 \%$ used in the checkerboard test (Figs. $4 \mathrm{a}$ and $5 \mathrm{a}$ ). However, the areas with a perturbation of $\pm 12 \%$ are located in the areas with fewer ray paths and the resolution was smeared. For the well-resolved areas the P-wave velocity perturbations are still within $\pm 5 \%$ as in the checkerboard test. The results indicate that at a depth of $0-3 \mathrm{~km}$, except at the central and southern segments of the CKF, the resolution is poor as the incident earthquake rays occurring within this depth range travel vertically and also have a relatively low ray density (Yeh et al. 2013). The resolutions at depths of $3-7$ and $7-12 \mathrm{~km}$ are remarkably good due to the fact

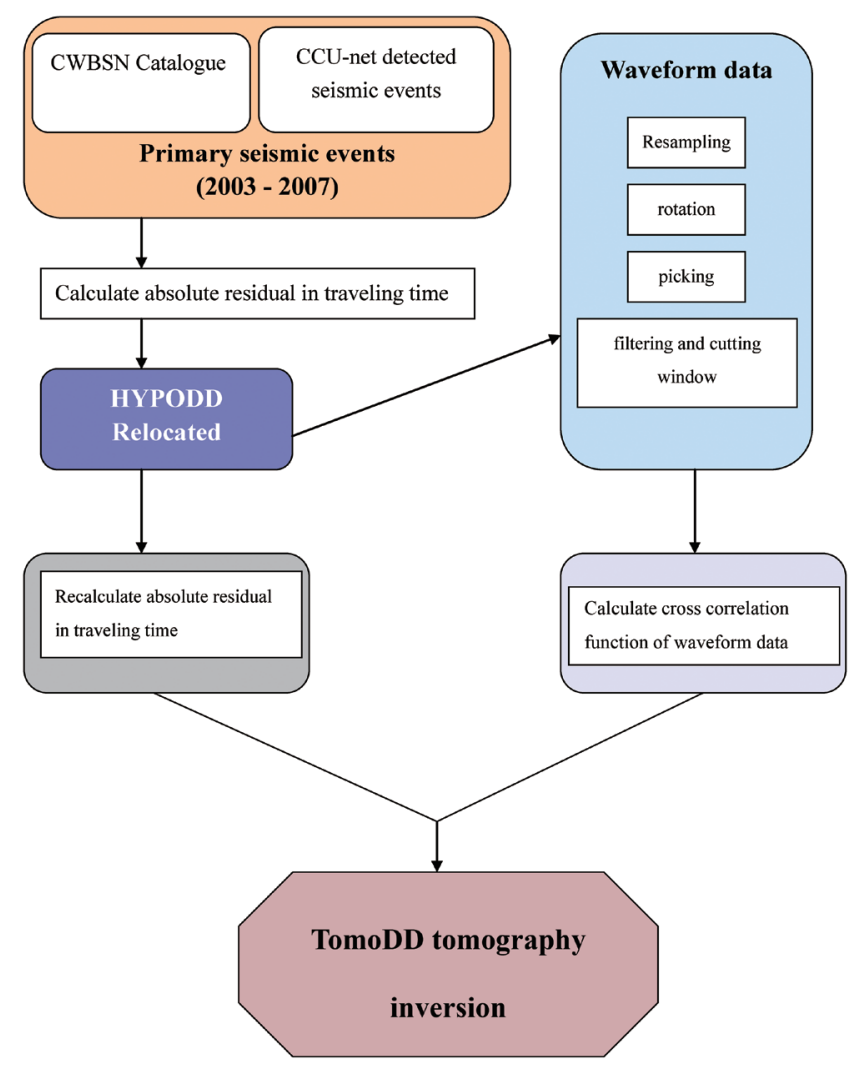

Fig. 2. Flow chart of data processing applied in this study. (Color online only) 

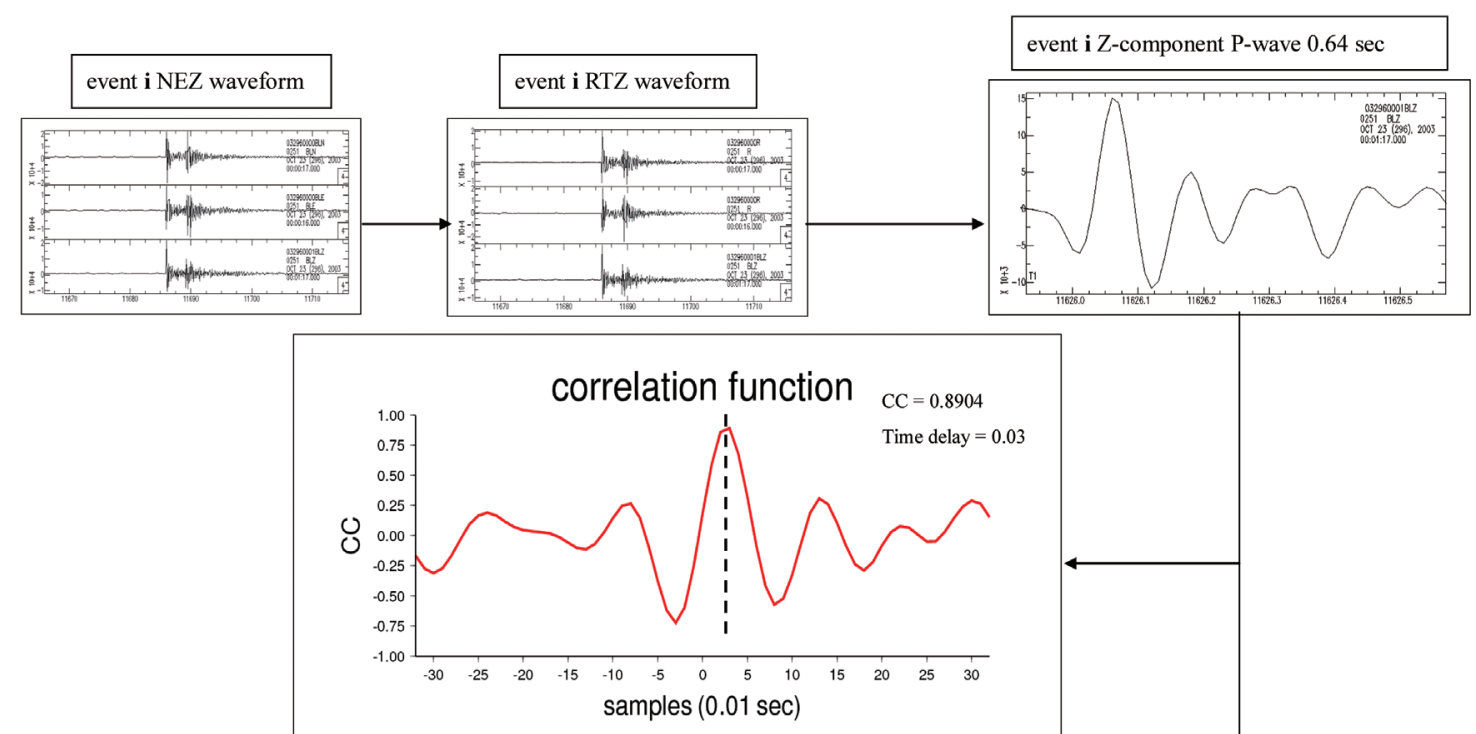

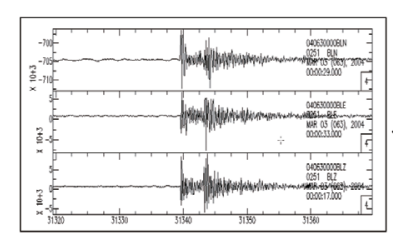

event $\mathbf{j}$ NEZ waveform

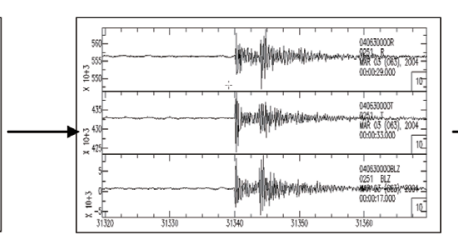

event $\mathbf{j}$ RTZ waveform

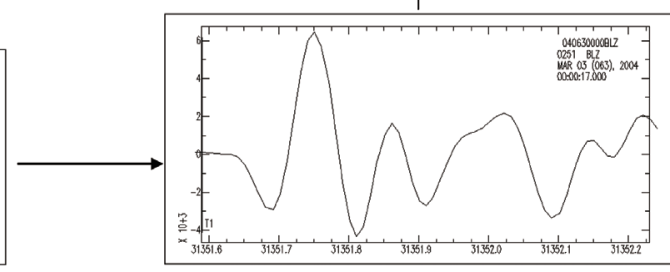

event j Z-component P-wave $0.64 \mathrm{sec}$

Fig. 3. A selected example showing the use of waveform cross-correlation (WCC) to estimate RDTT between the P-and S-waves. (Color online only)

Table 2. The information for the catalog and cross correlation data.

\begin{tabular}{c|cc}
\hline & Catalog (ct) & Cross Correlation (CC) \\
\hline P-wave pair & 187425 & 33725 \\
S-wave pair & 154777 & 30881 \\
\hline & 342202 & 143086 \\
\hline Total & & 485288 \\
& $70.5 \%$ & $29.5 \%$ \\
\hline
\end{tabular}

Table 3: P-wave velocity and $\mathrm{V}_{\mathrm{p}} / \mathrm{V}_{\mathrm{s}}$ ratio of 1D initial model (Yeh et al. 2013).

\begin{tabular}{ccc}
\hline Depth $(\mathbf{k m})$ & $\mathbf{V}_{\mathbf{p}}\left(\mathbf{k m ~ s e c} \mathbf{s e c}^{-1}\right)$ & $\mathbf{V}_{\mathbf{p}} / \mathbf{V}_{\mathbf{s}}$ \\
\hline $0-3$ & 4.08 & 1.78 \\
$3-7$ & 5.07 & 1.79 \\
$7-12$ & 5.11 & 1.78 \\
$12-17$ & 5.76 & 1.83 \\
$17-22$ & 6.21 & 1.74 \\
22 & 7.15 & 1.78 \\
\hline
\end{tabular}


(a)
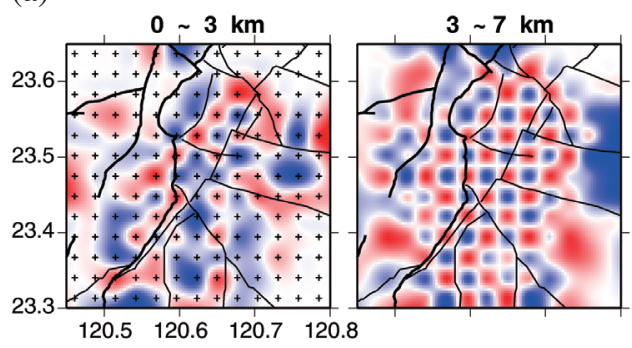

Vp-Checkerboard

(b)
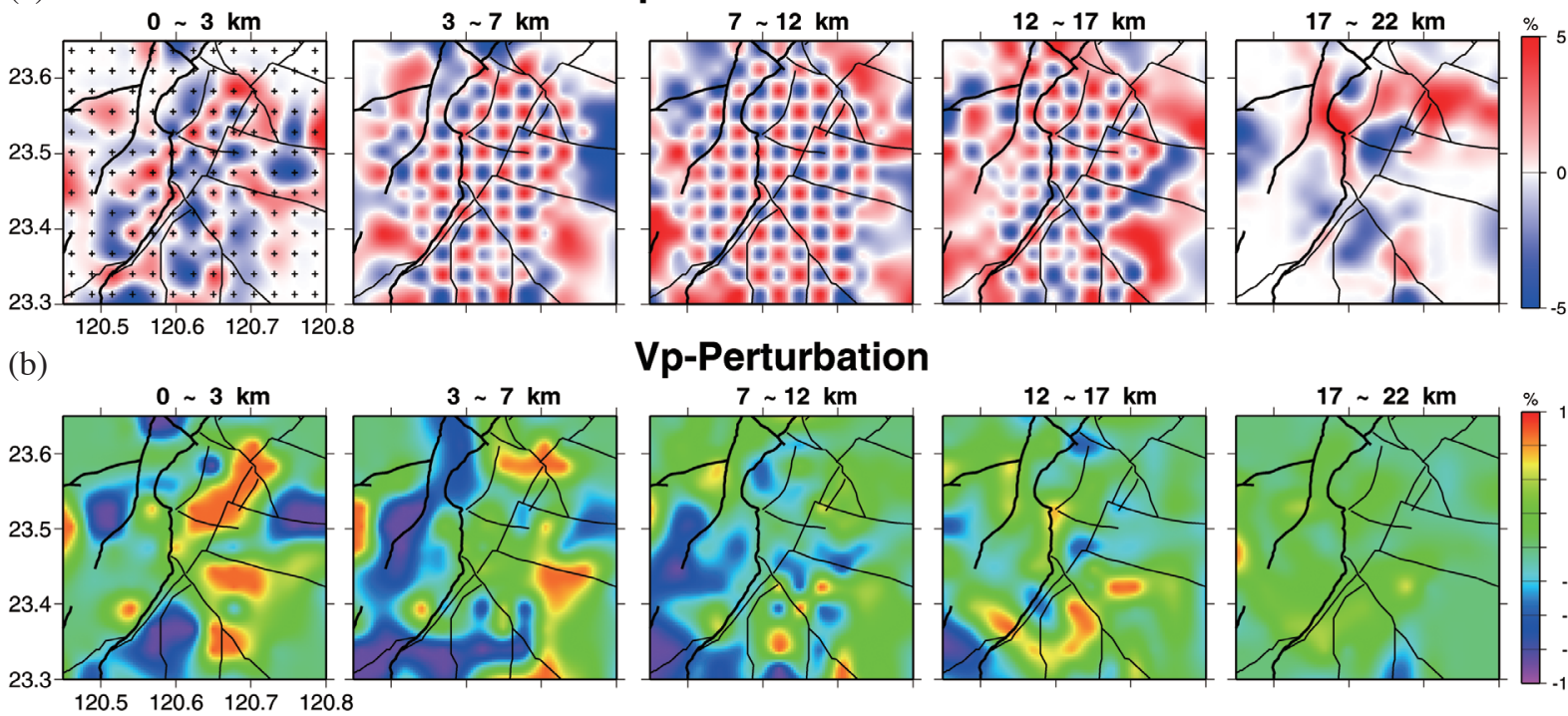

\section{Vp-Perturbation}
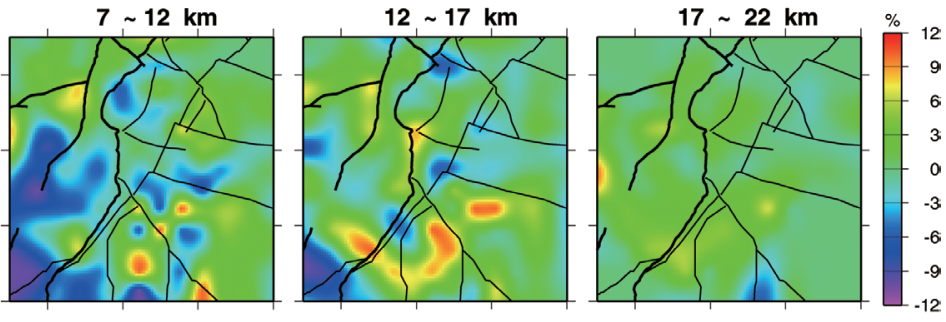

Fig. 4. (a) Checkerboard resolution tests in different depths. Positive and negative velocity perturbations are alternatively placed in the model. (b) Tomographic $\mathrm{P}$-wave perturbations in various depths. (Color online only)

(a)

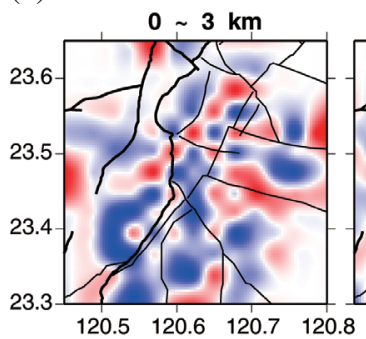

(b)

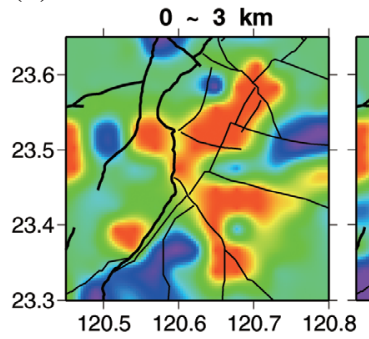

Vp/Vs-Checkerboard
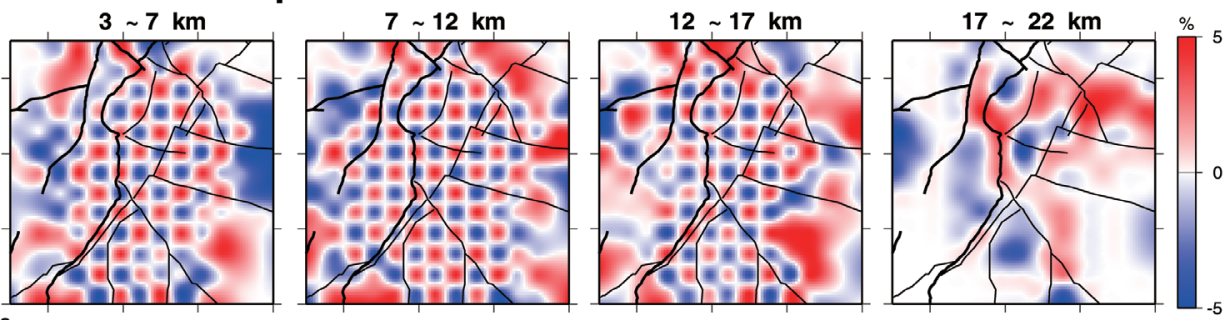

$\mathrm{Vp} / \mathrm{Vs}$
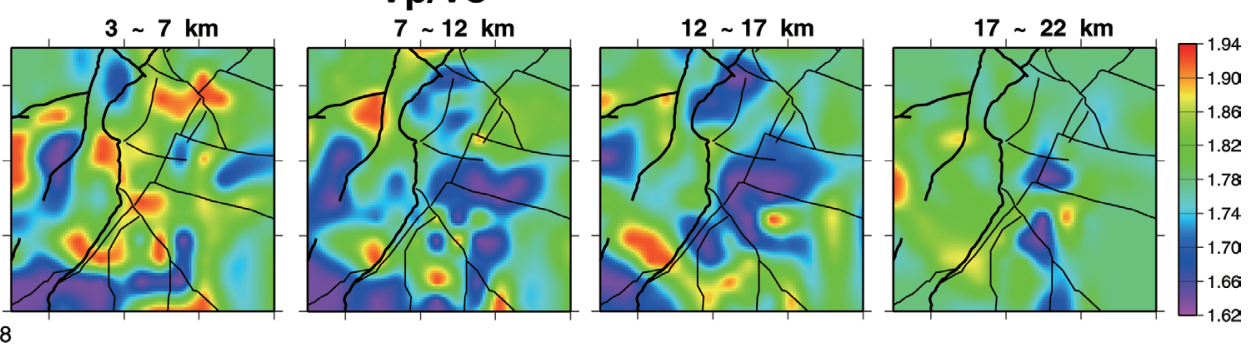

Fig. 5. (a) Checkerboard resolution tests in different depths. Positive and negative perturbations of $\mathrm{V}_{\mathrm{p}} / \mathrm{V}_{\mathrm{s}}$ ratios are alternatively placed in the model. (b) Tomographic $\mathrm{V}_{\mathrm{p}} / \mathrm{V}_{\mathrm{s}}$ ratios in different depths. (Color online only)

that most events occurred within these depth ranges, which lead to better spatial coverage of seismic rays. At a depth of $12-17 \mathrm{~km}$, the resolution in the east CKF is also well resolved. At a depth between 17 and $22 \mathrm{~km}$, the resolution decreases dramatically, which is due to fewer ray paths. Using the checkerboard test we demonstrate that the dataset used in this study is robust and has excellent spatial resolution for the upper crust.

\section{RESULTS AND DISCUSSIONS}

\subsection{Earthquake Relocation Using the TomoDD Technique}

Figure 6 depicts the variations in root-mean-square (RMS) misfit data with respect to the iteration number. The inversion residual using both the ADTT and the RDTT data (denoted by the solid red line) decreases significantly after 12 iterations as compared with the residual using the only ADTT data (denoted by the solid green line). It can be observed that the RMS drops from $0.75-0.3 \mathrm{~s}$ when using the ADTT data, while the residual decreases from $0.62-0.1 \mathrm{~s}$ 
when including the RDTT data. The epicenters of relocated events are plotted in Fig. 7 (denoted by the solid white circles). The results show that most events occurred between 5 and $15 \mathrm{~km}$ in the east CKF (Fig. 7). The CKF fault zone becomes aseismic at depths greater than $15 \mathrm{~km}$. The other finding after relocation is that several earthquake clusters were located in the east CKF. In order to understand the slip motion in our study area, events with magnitude $\mathrm{M}_{\mathrm{L}} \geq 3$ and recorded at more than eight stations with a high quality P-wave polarity were selected to obtain a focal mechanism using the FPFIT (Reasenberg and Oppenheimer 1985). The above results are also plotted along with velocity profiles shown in Figs. 7a - d. Interestingly, most events that occurred in the mid-crust or above the décollement were thrust types. Events that occurred in the lower crust were mostly dominated by high angle strike-slip motions (see the fault plane solutions in Figs. 7a - d). These strike-slip events may have resulted from the reactivation of preexisting normal faults (Brown et al. 2012).

\section{2 $\mathrm{V}_{\mathrm{p}}$ and $\mathrm{V}_{\mathrm{p}} / \mathrm{V}_{\mathrm{s}}$ Velocity Structures in the CKF Zone}

One of the important thin-skinned model themes proposed by Suppe (1981) is the imbricate fold-thrust belt formed above a décollement in the deformation front. Thus, the major challenge of this research is to investigate the role of décollement in our study area. The following sections will present the high resolution $\mathrm{V}_{\mathrm{p}}$ velocity images and $\mathrm{V}_{\mathrm{p}} / \mathrm{V}_{\mathrm{s}}$ ratios obtained by procedures described in section 3 . The results allow us to unveil the location of décollement and the significances of seismogenic structures in SW Taiwan.

\subsection{1 $\mathrm{V}_{\mathrm{p}}$ Velocity Images}

A major characteristic of the CKF zone is that its $V_{p}$ is relatively high in the east, where it is composed of Tertiary metamorphic rock formations. A low $\mathrm{V}_{\mathrm{p}}$ velocity anomaly in the western CKF zone is clearly observed, particularly west of the CCKF and the southern end of the CKF at depths between 3 and $7 \mathrm{~km}$. The above features are comparable with the studies of Wen and Chen (2004) and Yeh et al. (2013), who pointed out that the lower $\mathrm{V}_{\mathrm{p}}$ and $\mathrm{V}_{\mathrm{s}}$ in the uppermost crust is caused by unconsolidated sediments in west of the CKF. At depths from $3-12 \mathrm{~km}$, significant lateral velocity heterogeneity is observed. At depths greater than $12 \mathrm{~km}$, the velocity contrast begins to diminish, particularly from the mid- to the southern CKF segment (Fig. 4b). The results indicate that the strong velocity heterogeneity at depths less than $7 \mathrm{~km}$ is related to complex and highly deformed geological structures. Lateral variations fade out at depths greater than $7 \mathrm{~km}$, which may be due to uniform lithology with weak deformation.

\subsection{2 $\mathrm{V}_{\mathrm{p}} / \mathrm{V}_{\mathrm{s}}$ Images}

Figure $5 b$ shows the 3-D $V_{p} / V_{s}$ ratios in different layers, and the results strongly indicate prominent depth dependent heterogeneity. At a depth of $0-3 \mathrm{~km}$ the $\mathrm{V}_{\mathrm{p}} / \mathrm{V}_{\mathrm{s}}$ ratios in east of the CKF are generally higher than that in the west. A prominent high $\mathrm{V}_{\mathrm{p}} / \mathrm{V}_{\mathrm{s}}$ ratio is located east of the Shihkuping Fault (SKPF), which may indicate a highly fractured uppermost crust (Wen et al. 2008). Another high anomaly is in the east of the Laitou Fault (LTF), however, the resolution is poor and cannot be interpreted further (Fig. 5a). As the depth increases from $3-7 \mathrm{~km}$, the $\mathrm{V}_{\mathrm{p}} / \mathrm{V}_{\mathrm{s}}$ ratios in the CKF hanging wall depicts strong heterogeneity and the area with high $\mathrm{V}_{\mathrm{p}} / \mathrm{V}_{\mathrm{s}}$ ratios at a depth of $0-3 \mathrm{~km}$ begins to decrease. There is a low $\mathrm{V}_{\mathrm{p}} / \mathrm{V}_{\mathrm{s}}$ anomaly in both the southern segment of the CCKF and the CKF. We also observed along strike variations in $\mathrm{V}_{\mathrm{p}} / \mathrm{V}_{\mathrm{s}}$ ratios from the north to the south in the CKF, which may be related to the heterogeneous lithology in different CKF segments. The uppermost crust has higher $\mathrm{V}_{\mathrm{p}} /$ $\mathrm{V}_{\mathrm{s}}$ ratios than the middle crust. This feature may be associated with the change in lithology at a depth of $7 \mathrm{~km}$, from sedimentary to metamorphic type.

At depths between 7 and $12 \mathrm{~km}$, especially in the southernmost of the CKF, we can observe low and high $\mathrm{V}_{\mathrm{p}} / \mathrm{V}_{\mathrm{s}}$ ratios adjacent to each other across several sub-faults, which indicate complex imbricate structures beneath this area.

\subsection{Segmentation of the CKF Zone}

In order to understand the CKF segmentation signatures we investigated four velocity profiles (see Fig. 7). A detailed discussion of each profile is described in the following:

(1) A-A' profile: This profile is across the northern CKF segment and trends in the NW-SE direction, which is $18 \mathrm{~km}$ long and $6 \mathrm{~km}$ wide. The profile is across the Tachienshan Fault (TASF), the SKPF, the Luku Fault (LKF), and the Shechiunhu Fault (SCHF) from west to east. After event relocation, most earthquakes occurred at depths

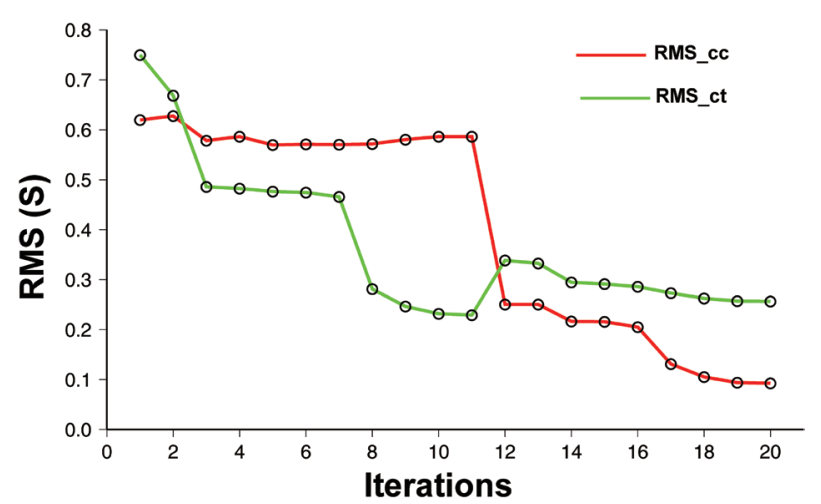

Fig. 6. The root-mean-square (RMS) plot with respect to the number of iterations in travel time inversion. The residual from using the combination of the ADTT and the RDTT data (denoted by the solid red line) decrease significantly after 6 iterations compared with using the ADTT data alone (denoted by the solid green line). (Color online only) 

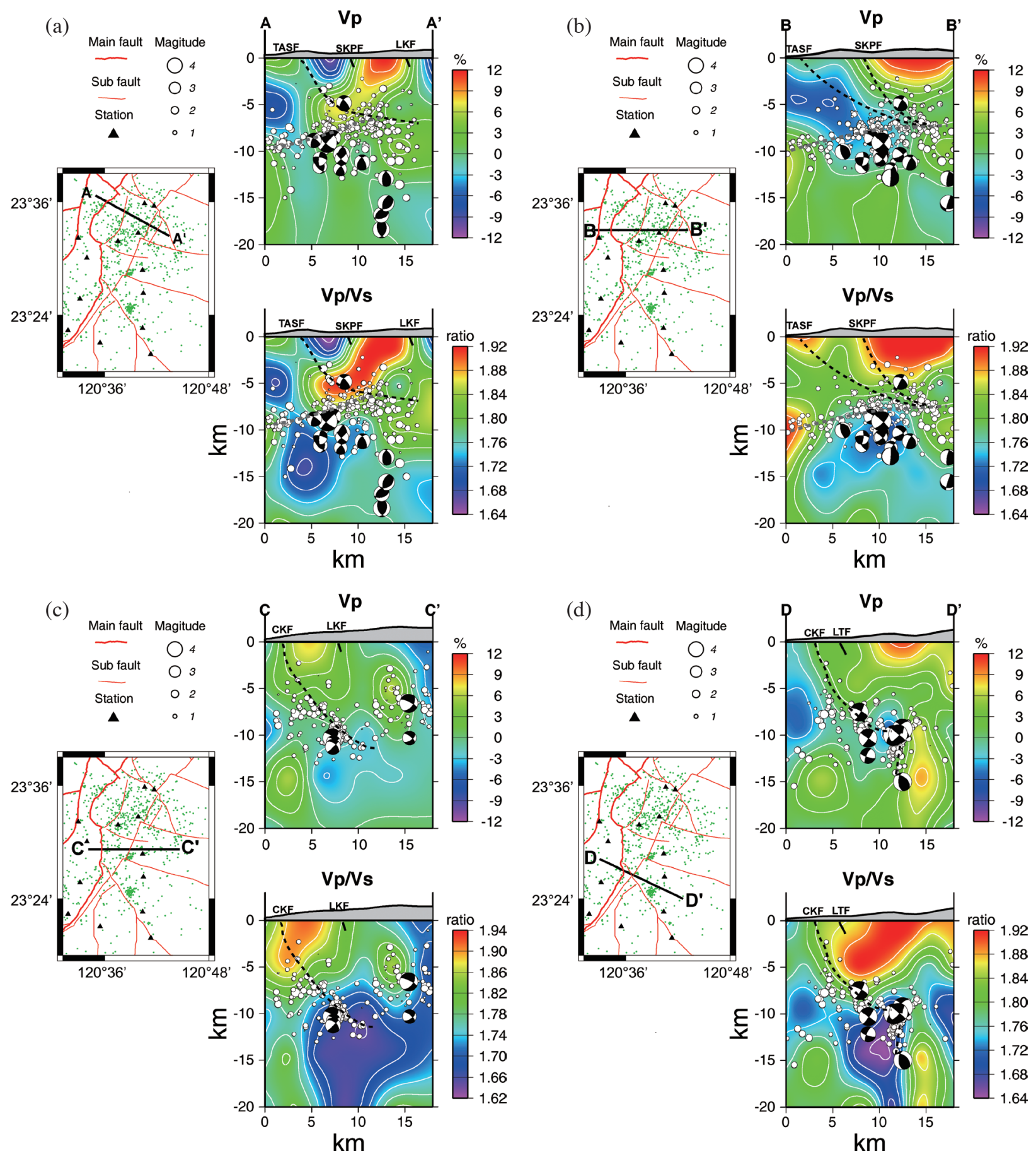

Fig. 7. Four velocity profiles (AA', BB', CC', and DD') across the CKF and the sub-faults located east of the CKF. The location of each profile and symbol legend is shown on the left-hand side in each figure. On the right-hand side, the top panel shows the tomographic $\mathrm{V}_{\mathrm{p}}$ perturbations along the profile, while the bottom panel depicts tomographic $\mathrm{V}_{\mathrm{p}} / \mathrm{V}_{\mathrm{s}}$ ratios. White solid circles denote relocated events. The focal mechanisms were obtained by applying the FPFIT technique using lower hemisphere projection. The focal mechanisms of events with $\mathrm{M}_{\mathrm{L}} \geq 3$ are plotted. (a) The black and grey dashed lines infer the Tachienshan Fault (TASF) geometry and a west-dipping seismic zone respectively. The locations of sub-faults, Shihkuping Fault (SKPF) and Luku Fault (LKF) are also indicated by black line segments, (b) the two black dashed lines infer the TASF and SKPF geometry, while the grey dashed line indicates a west-dipping seismic zone, (c) the black dashed line infers the CKF geometry along C-C'. The black line segment denotes the location of a sub-fault, LKF, (d) the black dashed line infers the CKF geometry along D-D'. The location of a sub-fault, LTF, is indicated by a black line segment. (Color online only) 
between 7 and $15 \mathrm{~km}$. Furthermore, deeper earthquakes occurred in an inclined zone which towards to east. The black dashed line indicates the TASF geometry, while the grey dashed line delineates a west dipping seismogenic zone located west of the SKPF. There is also an eastward dipping low $\mathrm{V}_{\mathrm{p}}$ zone right beneath the LKF. Another significant feature is a strong contrast in $\mathrm{V}_{\mathrm{p}}$ and $\mathrm{V}_{\mathrm{p}} / \mathrm{V}_{\mathrm{s}}$ ratios along the A-A' profile from west to east. The boundary between different faults is clearly defined by a prominent contrast in $\mathrm{V}_{\mathrm{p}}$ velocity and $\mathrm{V}_{\mathrm{p}} / \mathrm{V}_{\mathrm{s}}$ ratios. Despite this, one interesting feature is that the type of slip motion derived from the focal mechanism analysis is depth dependent. The focal mechanisms in the uppermost crust (depths less than $8 \mathrm{~km}$ ) show thrust types, while in the mid-crust is dominated by high-angle strike slip types (Fig. 7a).

(2) B-B' profile: The profile is about $18 \mathrm{~km}$ long and $6 \mathrm{~km}$ wide and perpendicular to the TASF. The profile is also across three sub-faults, including the SKPF, the LKF, and the SCHF. The earthquake cluster phenomenon is more obvious compared with that along the profile A-A'. One noticeable feature is the spatial distribution of hypocenters as most earthquakes occur in shallower depths $(\sim 7 \mathrm{~km})$ beneath the SKPF and the bending area at a depth of $7 \mathrm{~km}$. The depths of seismic events begin to get deeper westward and go toward the TASF. Interestingly, most earthquakes occurred in the region presented a sharp change in P-wave velocity. Each fault therefore appears to be associated with a prominent seismic velocity contrast. Similar to the A-A' profile, a west-dipping seismic zone also exists (Fig. 7b). However, the slip motion inferred from focal mechanisms is mostly in thrust type from the upper crust to the mid-crust.

(3) C-C' profile: This profile is across the central CKF segment and a sub-fault, LKF. A seismic zone dipping eastward is found beneath the CKF at depths from $5-12 \mathrm{~km}$ (denoted by the black dashed line). There also exists an eminent sharp change in the $\mathrm{V}_{\mathrm{p}} / \mathrm{V}_{\mathrm{s}}$ ratio at a depth of $7 \mathrm{~km}$. The slip motion is controlled by thrust type (Fig. 7c).

(4) D-D' profile: This profile is across the southern CKF segment and the LTF. The trend of this profile is similar to the plate collision direction in Taiwan. There are two groups of seismicity. One group of earthquakes is located at the boundary of the high and low $\mathrm{V}_{\mathrm{p}} / \mathrm{V}_{\mathrm{s}}$ ratios and clearly delineates the basal décollement toward the east. The slip motion is also ruled by thrust type (Fig. 7d). The other group has a vertical seismic zone at a depth from 10 - $15 \mathrm{~km}$ with a low $\mathrm{V}_{\mathrm{p}} / \mathrm{V}_{\mathrm{s}}$ ratio beneath the LTF, which is a high-angle strike-slip type fault. A prominent low and high $\mathrm{V}_{\mathrm{p}}$ and $\mathrm{V}_{\mathrm{p}} / \mathrm{V}_{\mathrm{s}}$ boundary exists at a depth of $7 \mathrm{~km}$ beneath the LTF.

In summary, most microearthquakes occurred at depths between 5 and $15 \mathrm{~km}$. The major active faults, such as the CKF and several sub-faults are well defined by the boundary between low and high $\mathrm{V}_{\mathrm{p}}$ velocity. A high contrast of $\mathrm{V}_{\mathrm{p}}$ and $\mathrm{V}_{\mathrm{p}} / \mathrm{V}_{\mathrm{s}}$ between 7 and $15 \mathrm{~km}$ in depth was clearly shown, where most microearthquakes occur. At depths greater than $15 \mathrm{~km}$ the seismicity is greatly decreased. We conclude that the depth of décollement in our study area is between 7 and $15 \mathrm{~km}$, which agrees with the characteristic of "décollement" propose by Suppe (1981). In addition, Brown et al. (2012) conducted an analysis of geological mapping, focal mechanism and seismic energy release and found that the foreland basin part of the WF in Taiwan exhibited an imbricate thrust system. They also suggested that the basal detachment location is between 7 and $10 \mathrm{~km}$ in depth, which is similar to our findings. Due to the limited resolution in the deeper part (25 - $30 \mathrm{~km}$ or greater) of our tomography model, our results could not identify the steeply dipping active faults in the lower crust associated with the Mesozoic basement with the reactivation of preexisting faults as indicated by Brown et al. (2012).

\section{CONCLUSIONS}

This study is the first attempt at monitoring the seismic activities in the CKF zone following the 1999 Chi-Chi earthquake. Detailed tomography structures were obtained via a dense temporal array. The results indicate that combining both ADTT and RDTT between P- and S-waves can greatly improve the accuracy of a seismic event location, which can lead to a more precise seismic velocity structure. Our results indicate that the main fault and sub-fault locations can be clearly defined and correlated with sharp boundaries of high- and low- $\mathrm{V}_{\mathrm{p}}$ velocity as well as a high contrast in $\mathrm{V}_{\mathrm{p}} / \mathrm{V}_{\mathrm{s}}$ ratios. The uppermost crust presents strong lateral heterogeneity in $\mathrm{P}$-wave velocity structures and $\mathrm{V}_{\mathrm{p}} / \mathrm{V}_{\mathrm{s}}$ ratios, which may result in complex geological structures on the surface. At depths greater than $7 \mathrm{~km}$, the lithology becomes more uniform and less deformed with high $\mathrm{V}_{\mathrm{p}} / \mathrm{V}_{\mathrm{s}}$ ratios. Furthermore, the lateral variation in velocity fades away. From the spatial distribution of P-wave velocity, evident segmentation in the CKF is observed. The central CKF segment demonstrates a typical imbricate fault belt. The southern CKF segment shows much less seismic activity. The 3-D velocity model derived in this study provides new perspectives and constraints on the physical properties of the seismogenic zone in SW Taiwan.

Acknowledgements We would like to thank the Taiwan Central Weather Bureau for providing high quality data. We also are in debt to Dr. Wei-Hau Wang who made critical and valuable comments on this manuscript. This research is supported by MOST-103-2116-M-492-004.

\section{REFERENCES}

Brown, D., J. Alvarez-Marron, M. Schimmel, Y. M. Wu, and G. Camanni, 2012: The structure and kinematics 
of the central Taiwan mountain belt derived from geological and seismicity data. Tectonics, 31, TC5013, doi: 10.1029/2012TC003156. [Link]

Chen, C. H., W. H. Wang, and T. L. Teng, 2003: Tectonic Implications of 1998, Ruey-Li, Taiwan, Earthquake sequence. Terr. Atmos. Ocean. Sci., 14, 27-40.

Dahlen, F. A. and T. D. Barr, 1989: Brittle frictional mountain building: 1. Deformation and mechanical energy budget. J. Geophys. Res., 94, 3906-3922, doi: 10.1029/ JB094iB04p03906 . [Link]

Kim, K. H., J. M. Chiu, J. Pujol, K. C. Chen, B. S. Huang, Y. H. Yeh, and P. Shen, 2005: Three-dimensional $V_{P}$ and $V_{S}$ structural models associated with the active subduction and collision tectonics in the Taiwan region. Geophys. J. Int., 162, 204-220, doi: 10.1111/j.1365246X.2005.02657.x. [Link]

Kuo-Chen, H., F. T. Wu, and S. W. Roecker, 2012: Threedimensional $\mathrm{P}$ velocity structures of the lithosphere beneath Taiwan from the analysis of TAIGER and related seismic data sets. J. Geophys. Res., 117, B06306, doi: 10.1029/2011JB009108. [Link]

Lee, W. H. K. and J. C. Lahr, 1972: HYP071: A computer program for determining hypocenter, magnitude, and first motion pattern of local earthquakes. Open File Report, U.S. Geological Survey, 100 pp.

Ma, K. F., J. H. Wang, and D. Zhao, 1996: Three-dimensional seismic velocity structure of the crust and uppermost mantle beneath Taiwan. J. Phys. Earth, 44, 85-105, doi: 10.4294/jpe1952.44.85. [Link]

Rau, R. J. and F. T. Wu, 1995: Tomographic imaging of lithospheric structures under Taiwan. Earth Planet. Sci. Lett.,133,517-532, doi: 10.1016/0012-821X(95)00076O. [Link]

Reasenberg, P. and D. Oppenheimer, 1985: FPFIT, FPPLOT, and FPPAGE: Fortran computer programs for calculating and displaying earthquake fault-plane solutions. Open-File Report, No. 85-739, U.S. Geological Survey, $109 \mathrm{pp}$.

Suppe, J., 1981: Mechanics of mountain building and metamorphism in Taiwan. Mem. Geol. Soc. China, $\mathbf{4}$, 67-89.

Suppe, J., 1985: Principles of Structural Geology, Prentice Hall, New Jersey, 537 pp.

Waldhauser, F. and W. L. Ellsworth, 2000: A doubledifference earthquake location algorithm: Method and application to the northern Hayward fault, California. Bull. Seismol. Soc. Am., 90, 1353-1368, doi: 10.1785/0120000006. [Link]

Wang, Z., Y. Fukao, D. Zhao, S. Kodaira, O. P. Mishra, and A. Yamada, 2009: Structural heterogeneities in the crust and upper mantle beneath Taiwan. Tectonophysics, 476, 460-477, doi: 10.1016/j.tecto.2009.07.018. [Link]

Wen, S. and C. H. Chen, 2004: 3-D velocity structure beneath the Chia-Nan area, Taiwan. Terr. Atmos. Ocean. Sci., 15, 239-259.

Wen, S., C. H. Chen, and T. L. Teng, 2008: Ruptures in a highly fractured upper crust. Pure Appl. Geophys., 165, 201-213, doi: 10.1007/s00024-008-0297-9. [Link]

Wu, F. T., R. J. Rau, and D. Salzberg, 1997: Taiwan orogeny: Thin-skinned or lithospheric collision? Tectonophysics, 274, 191-220, doi: 10.1016/S0040-1951(96)00304-6. [Link]

Wu, Y. M., C. H. Chang, L. Zhao, J. B. H. Shyu, Y. G. Chen, K. Sieh, and J. P. Avouac, 2007: Seismic tomography of Taiwan: Improved constraints from a dense network of strong motion stations. J. Geophys. Res., 112, B08312, doi: 10.1029/2007JB004983. [Link]

Yeh, Y. L., S. Wen, K. J. Lee, and C. H. Chen, 2013: Shearwave velocity model of the Chukuo fault zone, Southwest Taiwan, from cross correlation of seismic ambient noise. J. Asian Earth Sci., 75, 174-182, doi: 10.1016/j. jseaes.2013.07.023. [Link]

Yu, S. B. and H. Y. Chen, 1998: Strain accumulation in southwestern Taiwan. Terr. Atmos. Ocean. Sci., 9, 31-50.

Zhang, H. and C. H. Thurber, 2003: Double-difference tomography: The method and its application to the Hayward fault, California. Bull. Seismol. Soc. Am., 93, 1875-1889, doi: 10.1785/0120020190. [Link] 